\title{
Uveal Melanoma pM1c TNM Finding v8
}

National Cancer Institute

\section{Source}

National Cancer Institute. Uveal Melanoma pM1c TNM Finding v8. NCI Thesaurus. Code C140616.

Uveal melanoma with largest diameter of the largest metastasis $8.1 \mathrm{~cm}$ or more. (from AJCC 8th Ed.) 